\title{
Effectiveness of Cognitive Retraining In Chronic Mental Illness
}

$$
\text { Ashwini } D^{1 *} \text {, Rejani T.G }{ }^{1} \text {, Chauhan, } \text { A }^{2}
$$

\section{ABSTRACT}

Introduction: Cognitive impairment is the core feature in several chronic mental illnesses like schizophrenia and bipolar mood disorder. Its effect permeates to areas like work, social relationships and capacity for independent living. It determines the rate of rehabilitation and there lies the need to study cognitive retraining as a measure of effectiveness for psychiatric rehabilitation. Method: A sample of 10 patients was chosen for the study educated upto a minimum of $\mathrm{V}^{\text {th }}$ Grade and aged between 30-45 years. All ten patients were assessed prior to intervention and post intervention on Brief Psychiatric Rating Scale, Global Assessment of Functioning and selected tests from NIMHANS neuropsychological battery for adults (Color trails test, Stroop test, NBack test and WCST). Five patients were randomly selected for cognitive retraining (12 sessions for 4 weeks, 3 sessions each week for one hour). Results \& Conclusion: The analysis of scores at post intervention suggested no statistically significant differences in performance of intervention group and control group in the areas of attention, working memory, response inhibition and set shifting. However differences in mean for time taken on color trails and total correct scores, total errors and overall stroop effect, indicates a positive trend for improvement in these functions in the intervention group post cognitive retraining. The one month intervention duration is a likely limiting factor.

Keywords: Cognitive Retraining, Rehabilitation, Chronic Mental Illness.

Psychiatric rehabilitation denotes a wide range of interventions designed to help people with disabilities caused by mental illness to improve their functioning and quality of life by enabling them to acquire the skills and support required to be successful. It also enables them to deliver the expected adult roles in the environment of their choice (Drake et al, 2005)

Integrated pharmacological and psychosocial treatments, flexibly adapted to patients, changing needs and interests have been shown to yield better symptom control and higher level of community functioning. The treatment needs to be comprehensive, consistent, coordinated and competency based to achieve optimal outcomes (Adair et al.2005)

\footnotetext{
${ }^{1}$ Gujarat Forensic Sciences University, Gandhinagar

${ }^{2}$ Medical Superintendent, Hospital for Mental Health, Ahmedabad

*Responding Author

(C) 2016 I D Ashwini, T Rejani, A Chauhan; licensee IJIP. This is an Open Access Research distributed under the terms of the Creative Commons Attribution License (http://creativecommons.org/licenses/by/2.0), which permits unrestricted use, distribution, and reproduction in any Medium, provided the original work is properly cited.
} 


\section{Effectiveness of Cognitive Retraining In Chronic Mental Illness}

Executive functions are set of mental skills that are co-ordinated in brain's frontal lobe which includes organization, regulation, planning, problem solving, etc. Executive functioning is impaired in schizophrenia which means difficulty in one or more of the above cognitive areas (Morice and Delahunly, 1996.Mahurim et al., 1998. and Bryson et al.,2001).Executive deficits have a substantial impact on functional outcomes (Semkovska et al., 2004, Altshuler et al., 2007 and Bowie et al., 2008) and are closely related to chronicity (Greenwood et al., 2008).

Deficits in attention and information processing are central to schizophrenia and these contribute to deficits in working memory and executive functions (Braff, 1993). Such deficits are present in more complex measures of social cue recognition and 'theory of mind' (Greig, Bryson, \& Bell, 2004). Theory of mind (ToM) refers to the ability of an individual to make inferences about what others may be thinking or feeling and to predict what they may do in a given situation based on those inferences. (Schingler,2009) These cognitive deficits can be categorized into three major categories: a) the primary processes which includes attention, information processing and perception. b) the secondary processes which include executive functions \& memory. c) meta processes which includes insight (Rao, 2004).

The increasing awareness of the central role of cognitive deficits in schizophrenia has fostered considerable interest in the prospects of cognitive rehabilitation. The initial studies to investigate the generalization of cognitive retraining to tasks other than specifically trained function in schizophrenia patients were carried out by Wagner (1968) and Meichenbaum (1973). Almost a decade later, two studies rekindled interest in the application of cognitive retraining in schizophrenia. The authors concluded that a basic neurocognitive deficit owing to brain dysfunction made such rehabilitation impossible. Integrated Psychological Therapy (IPT), a comprehensive program to improve social competence by first enhancing basic cognitive skills was demonstrated by Brenner, Hodel, Roder, \& Corrigan (1992) and results indicated role of cognitive rehabilitation in the treatment of schizophrenia.

Bell et al. (2008) conducted a study to understand whether people with schizophrenia improve after cognitive retraining on attention tasks, whether individual performance varies by task, and what task improvement measures relate to pre-post-change in neuropsychological tests of attention. Thirty-two outpatients with schizophrenia or schizoaffective disorder completed at least 40 cognitive training hours on two computerized visual attention training tasks (VT1 and VT2) and pre-post-testing with Digit Span, Digit Symbol Substitution Task, and Continuous Performance Task and found that cognitive training was effective in improving task performance but that similar tasks can be different in who performs well and what components of attention may be affected.

Most of the cognitive retraining programs aim to improve the cognitive domains usually associated with deficits in schizophrenia-for instance verbal and visual working memory, 


\section{Effectiveness of Cognitive Retraining In Chronic Mental Illness}

executive function, attention, and processing speed. This is a top-down approach in which the target of training is a higher-order cognitive process (Hurford et al,2011).

Fisher and colleagues adopted a computerized remediation program called Posit Science which focused on early auditory and visual sensory processes, such as tone and phoneme discrimination, as well as higher-order cognitive processes, such as verbal memory. Vinogradov believes that focusing on early sensory processing in schizophrenia is important because previous research findings indicate that there are early sensory processing deficits in schizophrenia (Hurford et al, 2011)

Schiavon, et al (2013) did systematic review on retraining for executive functioning deficit on schizophrenia. For that they reviewed 184 articles on the basis of which they found cognitive retraining could improve cognitive domains and social adjustment either using computerized or paper-and-pencil programs.

To date, there has been no head-to-head comparison of bottom-up and top-down approaches and almost all cognitive retraining programs use at least some repetitive practice of cognitive exercises to target domains of deficit, many also include other unique components beyond drill and practice (Hurford, et al, 2011) The duration of cognitive retraining programs being highly demanding, there is a need to establish the effectiveness of a cognitive retraining program in patients with chronic and severe mental illness; similar to neurological conditions Hence the present study was planned on understanding the effectiveness of a cognitive retraining program.

\section{METHODOLOGY}

The aim of the study was to understand the effectiveness of cognitive retaining in chronic mental illness.

\section{The objectives of the study were:}

1) To study the impact of cognitive retraining on global functioning and severity of psychopathology.

2) To study the effectiveness of cognitive retraining on attention.

3) To study the effectiveness of cognitive retraining on working memory in patients.

4) To study the effectiveness of cognitive retraining on executive functions like set- shifting and response inhibition.

\section{Sample:}

A sample of 10 patients ( males and females), aged between 30 years to 45 years educated up to minimum $5^{\text {th }}$ Grade level, admitted in Hospital For Mental Health, Ahmadabad since 5-10 years were chosen for the study. Out of which five of them underwent the cognitive remediation programme whereas the other five patients were waitlisted for intervention as waitlist controls. The inclusion criteria being: 


\section{Effectiveness of Cognitive Retraining In Chronic Mental Illness}

- Patients with diagnosis of F20-F29: Schizophrenia, schizotypal and delusional disorders or F30-F39: Mood [affective] disorders according to ICD-10 guidelines.

- Duration of Illness 7 years or more.

- Minimum education level $\mathrm{V}^{\text {th }}$ Grade were included as sample.

\section{Tools:}

The tools used for data collection were Brief Psychiatric rating scale, Global assessment of Functioning and NIMHANS neuropsychological battery for adults (Color trails test, Stroop test, N Back test and Wisconsin Card Sorting Test).

\section{Procedure:}

All ten patients were assessed prior to intervention on Brief Psychiatric rating scale, global assessment of functioning and selected tests from NIMHANS neuropsychological battery for adults (Color trails test, Stroop test, NBack test and WCST). 5 patients were randomly selected for cognitive retraining (12 sessions for 4 weeks, 3 sessions each week for one hour).

\section{Intervention Package:}

The cognitive retraining package comprised of a number of tasks, out of which some were of graded difficulty from first to fourth week. For attention retraining, number and symbol cancellation tasks: single as well as double was used with graded difficulty. For visual working memory, 10 flash cards were used with geometric design and pictures which were arranged in order of increasing difficulty were presented to the participants. Whereas for verbal working memory retraining, grammatically incorrect jumbled sentences were used in order of increasing difficulty. For retraining of response inhibition, a sheet with different geometric shapes was used on which, the subject was asked to follow 'start' and 'stop' instructions and spontaneously change colouring of pattern as per the instructions. For set shifting three types of activities were planned as part of retraining: hand and foot tapping sequencing, card sorting and bead sorting in order of increasing difficulty.

Statistical Analysis was carried out using SPSS 20.0 version, independent samples t test to compare scores pre and post intervention within group and between groups was applied using non parametric test and also Wilcoxon's Signed Rank Test was applied to compare the errors, omission and commission scores pre and post assessment of neuropsychological functioning and to compare the scores of neuropsychological assessment of patients of waitlist controls. 


\section{RESULTS}

Table 1: Shows results of independent sample t test to compare groups on Education and Duration of illness

\begin{tabular}{|l|l|l|l|l|l|}
\hline Variables & Group & $\begin{array}{l}\text { Mean } \\
\text { (in } \\
\text { years) }\end{array}$ & $\begin{array}{l}\text { Standard } \\
\text { Deviation }\end{array}$ & $\mathbf{t}$ & $\begin{array}{l}\text { Significance } \\
\text { level }\end{array}$ \\
\hline Education & Intervention Group & 8.40 & 2.7 & 2.14 & 0.06 \\
& Control Group & 11.20 & 1.09 & 0 & 1.0 \\
\hline $\begin{array}{l}\text { Duration of } \\
\text { illness }\end{array}$ & Intervention Group & 10.8 & 5.5 & 0 & \\
\hline
\end{tabular}

$$
\mathrm{df}=8, \mathrm{p} \geq 0.05
$$

The results in the table show that the groups were comparable on the level of education (years) and duration of illness. The mean education level of intervention group was 8.40, standard deviation was 2.7 and for the control group the mean was 11.20 with a standard deviation of 1.09. This indicates that there is no statistically significant differences between the two groups on education level and the two groups are comparable.

On duration of illness, the mean duration of illness for the intervention group was 10.8 years, mean standard deviation was 5.5, whereas the mean duration of illness was also 10.8 years for control group with a standard deviation of 3.5 which suggests no statistically significant differences between two groups at pre- intervention level ( $\mathrm{t}=0, \mathrm{p}=1.0, \mathrm{p} \geq 0.05)$. Hence it can be said that the two groups were comparable prior to the intervention.

Table No 2: Showing results on Brief Psychiatric Rating Scale and Global assessment of functioning between the intervention group and waitlist controls pre and post intervention

\begin{tabular}{|l|l|l|}
\hline Scores/Areas & Pre Intervention & Post Intervention \\
\hline BPRS & 0.79 & 1.3 \\
\hline GAF & 0.7 & 0.7 \\
\hline
\end{tabular}

Table 2 shows the results of BPRS total score when compared pre intervention assessment to post intervention assessment, no statistically significant differences were found $(\mathrm{t}=0.79$, $\mathrm{p}=0.46, \mathrm{p}>0.05$ ). The assessment results prior to intervention showed no statistically significant difference, which suggests that the groups were comparable prior to intervention $(t=0.79$, $\mathrm{p}=0.76$ ). It was noticed that there was no change in total BPRS score as a result of intervention.

There were no significant differences in GAF total scores in assessment done pre and post intervention. On assessment done prior to intervention $\mathrm{t}=0.7, \mathrm{p}=0.4, \mathrm{p}>0.05$. Similarly on post intervention assessment no statistically significant differences were found $(t=0.7, p=0.46$, $\mathrm{p}>0.05$ ). This suggests no significant improvement in global functioning could be noticed as a result of intervention. 
Table 3: Shows results on independent samples t test to compare scores on color trails test pre and post intervention.

\begin{tabular}{|c|c|c|c|c|c|}
\hline Variables & Groups & Mean & SD & $\mathbf{t}$ & $\mathbf{p}$ \\
\hline \multirow{2}{*}{$\begin{array}{ll}\text { Color } & \text { Trails } \\
1 \text { (pre) }\end{array}$} & Intervention Group & 134 & 34.3 & \multirow{2}{*}{0.9} & \multirow{2}{*}{0.3} \\
\hline & Control Group & 107 & 53 & & \\
\hline \multirow{2}{*}{$\begin{array}{l}\text { Color Trails } \\
1 \text { (post) }\end{array}$} & Intervention Group & 99 & 38.6 & \multirow{2}{*}{0.1} & \multirow{2}{*}{0.3} \\
\hline & Control Group & 78 & 17.01 & & \\
\hline \multirow{2}{*}{$\begin{array}{ll}\text { Color } & \text { Trails } \\
2 \text { (pre) } & \end{array}$} & Intervention Group & 288 & 129 & \multirow{2}{*}{1.3} & \multirow{2}{*}{0.20} \\
\hline & Control Group & 187 & 98 & & \\
\hline \multirow{2}{*}{$\begin{array}{l}\text { Color Trails } \\
2 \text { (Post) }\end{array}$} & Intervention Group & 205 & 113 & \multirow{2}{*}{0.7} & \multirow{2}{*}{0.49} \\
\hline & Control Group & 162 & 76 & & \\
\hline
\end{tabular}

The results indicate that on color trails 1 there is no statistically significant difference between the groups at pre intervention assessment $(\mathrm{t}=0.9, \mathrm{p}=0.3)$ and post intervention no statistically significant differences were noted $(\mathrm{t}=0.9, \mathrm{p}=0.3)$ but differences in mean as the time taken to complete trail 1 in intervention group has reduced from 134 to 99 during post intervention assessment, suggesting slight improvement in performance as a result of intervention (difference in mean=35). Whereas the changes in the control group in time taken has reduced less compared to intervention group (difference in mean=25).

On color trails 2 also, no statistically significant differences were found between the groups at pre and post intervention on time taken to complete the color trail, $\mathrm{t}=0.7, \mathrm{p}=0.49$ at $\mathrm{df}=8 \mathrm{p}>0.05$. However, there were difference in mean in the intervention group (difference in mean $=83$ ) where as in the control group it was just 25 . Hence it can be said that there was slight improvement in focussed attention as a result of intervention, though it is not statistically significant.

Table no 4: Shows results on independent samples t test to compare scores on stroop test pre and post intervention.

\begin{tabular}{|c|c|c|c|c|c|c|}
\hline & Groups & Mean & SD & $t$ & df & $\mathbf{p}$ \\
\hline \multirow{2}{*}{$\begin{array}{l}\text { Stroop } \\
\text { effect (pre) }\end{array}$} & Intervention Group & 92 & 31.7 & \multirow{2}{*}{1.98} & \multirow[b]{2}{*}{8} & \multirow{2}{*}{0.08} \\
\hline & Control Group & 61 & 14.5 & & & \\
\hline \multirow{2}{*}{$\begin{array}{l}\text { Stroop } \\
\text { effect } \\
\text { (post) }\end{array}$} & Intervention Group & 73 & 32.5 & \multirow[b]{2}{*}{1.72} & \multirow[b]{2}{*}{8} & \multirow[b]{2}{*}{0.1} \\
\hline & Control Group & 45 & 16.3 & & & \\
\hline \multirow{2}{*}{$\begin{array}{l}\text { Condition } \\
1 \text { (pre) }\end{array}$} & Intervention Group & 128 & 37.1 & \multirow{2}{*}{0.26} & \multirow{2}{*}{8} & \multirow{2}{*}{0.79} \\
\hline & Control Group & 134 & 35.9 & & & \\
\hline \multirow{2}{*}{$\begin{array}{l}\text { Condition } \\
1 \text { (post) }\end{array}$} & Intervention Group & 127 & 34.5 & \multirow{2}{*}{0.36} & \multirow{2}{*}{8} & \multirow{2}{*}{0.72} \\
\hline & \begin{tabular}{|l|} 
Control Group \\
\end{tabular} & 135 & 38.9 & & & \\
\hline \multirow{2}{*}{$\begin{array}{l}\text { Condition } \\
2 \text { (pre) } \\
\end{array}$} & Intervention Group & 220 & 56.5 & \multirow{2}{*}{0.26} & \multirow{2}{*}{8} & \multirow{2}{*}{0.79} \\
\hline & Control Group & 191 & 43.8 & & & \\
\hline \multirow{2}{*}{$\begin{array}{l}\text { Condition } \\
2 \text { (post) } \\
\end{array}$} & Intervention Group & 194 & 46 & \multirow{2}{*}{0.8} & \multirow{2}{*}{8} & \multirow{2}{*}{0.7} \\
\hline & Control Group & 182 & 51 & & & \\
\hline
\end{tabular}




\section{Effectiveness of Cognitive Retraining In Chronic Mental Illness}

The results indicate that there are no statistically significant differences in time taken on condition 1 and condition 2 of stroop test at pre and post the intervention levels. On condition 1 pre intervention assessment statistically no significant differences were found between the groups $(\mathrm{t}=0.36, \mathrm{p}=0.7(\mathrm{p}>0.05)$.

On condition 2, post intervention ( $\mathrm{t}=0.8 \mathrm{p}=0.7, \mathrm{p}>0.05$ ) suggesting no significant difference as a result of intervention. Overall stroop effect there was no significant difference post intervention $(t=1.72, p=0.08 p>0.05)$. However, mean difference in intervention group was more than control group.

Table 5: Shows Wilcoxon's Signed Rank test to compare total correct, errors, perseverative error, responses and non perseverative errors on WCST post intervention of intervention and control group.

\begin{tabular}{|c|c|c|c|c|c|}
\hline & Groups & Sum ranks & $\begin{array}{l}\text { Mean } \\
\text { of } \\
\text { Ranks }\end{array}$ & $\mathbf{Z}$ & $\mathbf{P}$ \\
\hline \multirow[t]{2}{*}{ Total correct } & Negative ranks & 2.75 & 5.50 & \multirow[t]{2}{*}{0.54} & \multirow[t]{2}{*}{0.58} \\
\hline & Positive ranks & 3.17 & 9.5 & & \\
\hline \multirow{2}{*}{ Total Errors } & Negative ranks & 3.5 & 10.50 & \multirow{2}{*}{0.81} & \multirow{2}{*}{0.41} \\
\hline & Positive ranks & 2.25 & 4.5 & & \\
\hline \multirow{2}{*}{$\begin{array}{l}\text { Perseverative } \\
\text { responses }\end{array}$} & Negative ranks & 2.5 & 10.5 & \multirow{2}{*}{0.67} & \multirow{2}{*}{0.50} \\
\hline & Positive ranks & 5.0 & 5.0 & & \\
\hline \multirow{2}{*}{ Perseverative errors } & Negative ranks & 2.5 & 7.5 & \multirow{2}{*}{0.00} & \multirow{2}{*}{1.0} \\
\hline & Positive ranks & 3.75 & 7.5 & & \\
\hline \multirow{2}{*}{$\begin{array}{l}\text { Non-Perseverative } \\
\text { errors }\end{array}$} & Negative ranks & 3.13 & 12.50 & \multirow{2}{*}{1.3} & \multirow{2}{*}{0.17} \\
\hline & Positive ranks & 2.50 & 2.50 & & \\
\hline \multirow{2}{*}{$\begin{array}{ll}\begin{array}{l}\text { Concept } \\
\text { responses }\end{array} & \text { level }\end{array}$} & Negative ranks & 5.0 & 5.0 & \multirow{2}{*}{0.67} & \multirow{2}{*}{0.50} \\
\hline & Positive ranks & 2.5 & 10.0 & & \\
\hline \multirow{2}{*}{$\begin{array}{l}\text { Number of categories } \\
\text { completed }\end{array}$} & Negative ranks & 1.00 & 1.00 & \multirow{2}{*}{0.44} & \multirow{2}{*}{0.65} \\
\hline & Positive ranks & 2.00 & 2.00 & & \\
\hline
\end{tabular}

The results from table 5 suggests when post intervention scores of both control group and intervention group were analyzed at post intervention assessment, statistically no significant differences were found on total correct responses $(\mathrm{Z}=0.54, \mathrm{p}=0.58)$, total errors $(\mathrm{Z}=0.81$, $p=0.51)$, perseverative responses $(Z=0.67, p=0.50)$, perseverative errors $(Z=0.00, p=1)$ and nonperseverative errors $(Z=1.3, p=0.17)$ concept level responses $(Z=0.67, p=0.50)$ and number of categories completed $(Z=0.44, p=0.65)$. This suggests that on set shifting ability there were no statistically significant improvement noted between the groups as a result of intervention. 
Table 6: Shows Wilcoxon's Signed Rank test to compare correct/hits, omissions, commissions and total errors on Verbal working memory on $N$ Back test post intervention in the intervention group and control group:

\begin{tabular}{|c|c|c|c|c|c|}
\hline & Groups & Sum ranks & \begin{tabular}{|l|}
$\begin{array}{l}\text { Mean of } \\
\text { Ranks }\end{array}$ \\
\end{tabular} & $\mathbf{Z}$ & $\mathbf{p}$ \\
\hline \multirow{2}{*}{$\begin{array}{lr}\text { Verbal working } \\
\text { memory hits } \\
\text { (pre-post) }\end{array}$} & Negative ranks & 2.5 & 5 & \multirow[t]{2}{*}{0.00} & \multirow[t]{2}{*}{1.0} \\
\hline & Positive ranks & 2.5 & 5 & & \\
\hline \multirow{2}{*}{$\begin{array}{l}\text { Verbal Working } \\
\text { memory } \\
\text { omissions (pre- } \\
\text { post) }\end{array}$} & Negative ranks & 2.33 & 7 & \multirow[t]{2}{*}{0.1} & \multirow[t]{2}{*}{0.89} \\
\hline & Positive ranks & 4.00 & 8 & & \\
\hline \multirow{2}{*}{$\begin{array}{l}\text { Verbal working } \\
\text { memory } \\
\text { commissions } \\
\text { (pre-post) }\end{array}$} & Negative ranks & 1 & 1 & \multirow[b]{2}{*}{0.44} & \multirow[b]{2}{*}{0.65} \\
\hline & Positive ranks & 2 & 2 & & \\
\hline \multirow{2}{*}{$\begin{array}{l}\text { Verbal Working } \\
\text { memory errors }\end{array}$} & Negative ranks & 3.25 & 6.50 & \multirow{2}{*}{0.27} & \multirow{2}{*}{0.78} \\
\hline & Positive ranks & 2.83 & \begin{tabular}{|l|}
8.50 \\
\end{tabular} & & \\
\hline
\end{tabular}

The results on verbal working memory when compared between control group and intervention group shows no statistically significant difference on hits/ correct responses $(Z=0.00, p=1.00)$, omissions ( $\mathrm{Z}=0.1, \mathrm{p}=0.89$ ), commissions $(\mathrm{Z}=0.44, \mathrm{p}=0.65)$, errors $(\mathrm{Z}=0.27, \mathrm{p}=0.78)$. This suggests that statistically no significant improvement could be noted in the verbal working memory function in the intervention group and control group at post assessment.

Table 7: Shows Wilcoxon's Signed Rank test to compare correct/hits, omissions, commissions and total errors on Visual working memory on $\mathbf{N}$ Back test post intervention of intervention and control group.

\begin{tabular}{|c|c|c|c|c|c|}
\hline & Groups & Sum ranks & \begin{tabular}{|l|} 
Mean of \\
Ranks
\end{tabular} & $\mathbf{Z}$ & $\mathbf{p}$ \\
\hline \multirow{2}{*}{$\begin{array}{l}\text { Visual working } \\
\text { memory hits }\end{array}$} & Negative ranks & 2.83 & 8.5 & \multirow{2}{*}{0.27} & \multirow{2}{*}{0.78} \\
\hline & Positive ranks & 3.25 & 6.5 & & \\
\hline \multirow{2}{*}{$\begin{array}{l}\text { Visual Working } \\
\text { memory } \\
\text { omissions }\end{array}$} & Negative ranks & 3.25 & 6.5 & \multirow[t]{2}{*}{0.27} & \multirow[t]{2}{*}{0.78} \\
\hline & Positive ranks & 2.83 & 8.5 & & \\
\hline \multirow{2}{*}{$\begin{array}{l}\text { Visual working } \\
\text { memory } \\
\text { commission }\end{array}$} & Negative ranks & 3.5 & 7 & \multirow{2}{*}{0.7} & \multirow[b]{2}{*}{0.4} \\
\hline & Positive ranks & 1.5 & 3 & & \\
\hline \multirow{2}{*}{$\begin{array}{l}\text { Visual Working } \\
\text { memory errors }\end{array}$} & Negative ranks & 4.5 & 9 & \multirow{2}{*}{0.40} & \multirow{2}{*}{0.68} \\
\hline & Positive ranks & 2.0 & 6 & & \\
\hline
\end{tabular}




\section{Effectiveness of Cognitive Retraining In Chronic Mental Illness}

The results on visual working memory when compared between control group and intervention group shows no statistically significant difference on hits/ correct responses $(Z=0.27, p=0.78)$, omissions $(Z=0.27, p=0.78)$, commissions $(Z=0.7, p=0.4)$, errors $(Z=0.4, p=0.68)$. This suggests that statistically no significant improvement could be noted in the visual working memory function in the intervention group and control group at post assessment.

\section{DISCUSSION}

In a study conducted by Bell et al (2008) suggests that cognitive training focussed at attention tasks brings about improvement in cognitive symptoms. Metanalytical studies have also suggested that deficits of attention are central to most chronic illness and need to be addressed in cognitive retraining which have shown improvement (Trivedi, 2006). However, in the present study even though there were no statistically significant changes noted in performance, the consideration of differences in mean from pre intervention assessment to post intervention assessment in the intervention group definitely suggest that the focused attention, perceptual tracking and mental flexibility are on the path of improvement as a result of retraining. Increasing the number of sessions of cognitive retraining might give results similar to those found in earlier studies.

Impairment of working memory, sustained attention, focusing-execution, abstract reasoning and visuomotor skills, verbal memory, verbal fluency, visuospatial ability, have all been reported, even in the euthymic phase of the illness.(Trivedi, 2006). There have also been studies where researchers observed that manipulations of experimental stimuli (e.g., reduction in attentional demands, changes in stimulus characteristics) could produce improvements on laboratory tasks (Twamley, Jeste, \& Bellack, 2003) and ultimately on cognitive deficits like attention and working memory. However, in this study, no statistically significant improvement has been noted as a result of cognitive retraining in either working memory modalities, particularly in the intervention group. This may be suggestive of the limitation of the cognitive retraining task targeting verbal and visual working memory being not adequate or by increasing the duration of retraining task results similar to previous findings can be noted.

Set shifting ability regulates attention, speech, thought, emotion and social behaviour. It requires cognitive flexibility both in formation of mental set and in the subsequent shifting of the set (Delahunty,1993). Hence it is a relatively complex function which might take longer duration and intensive retraining to improve.

In the present study the increase in total correct responses and reduction in total errors in the intervention group suggests a positive trend towards gradual improvement provided the adequate retraining tasks is given for a longer duration. Also in chronic mental illness, this ability seems to be severely impaired; hence the findings are somewhat similar to previous studies, though no marked improvement can be noted in reduction of perseverative errors and responses 


\section{Effectiveness of Cognitive Retraining In Chronic Mental Illness}

Yet, some positive findings of improvement in some basic functions definitely explores the possibility of use of such a cognitive retraining package for a longer duration with most chronic mental illness, which will further not only help improve the global assessment of functioning of these individuals but also help to some extent in preventing relapse.

\section{CONCLUSION}

The aim of the study was to understand the effectiveness of cognitive retaining in chronic mental illness. Even though no significant statistical differences were found between the individuals who underwent intervention and who were waitlist controls in the areas of attention, set shifting, working memory, but mean differences were noticed in the area of focused attention and visual scanning suggesting a positive trend to cognitive enhancement. With some improvisations in the tasks targeting each functions and increasing the duration of administration of this package on a mixed group of patient suffering from chronic mental illness might definitely bring improvement in their cognitive deficits as well as psychosocial functioning.

\section{LIMITATIONS OF THE STUDY}

1. The study was planned for only one month i.e. 12 sessions. Hence no significant improvement or conclusive effectiveness could be established.

2. Other than vocational training, only cognitive retraining sessions were planned.

3. Some tasks seemed quite simple to the participants during retraining sessions. Hence they could be replaced or improvised keeping in mind the difficulty level and interests of the participants to bring out effectiveness.

\section{FUTURE DIRECTIONS}

After improvisation of some tasks of specific functions like set shifting, verbal and visual working memory the package could be applied to a larger sample size with varied diagnosis of chronic mental illness for minimum two months to see its effectiveness.

A cognitive retraining package which compares the effectiveness of top-down and bottom-up information processing approach along with the compensatory strategies of rehabilitation can be developed with a clear emphasis on more concrete goals.

A multimodality treatment along with this package will benefit the patient in improving his global or psychosocial functioning and will also ensure improvement.

\section{IMPLICATION OF THE STUDY}

A cognitive retraining package of this type may prevent the progression of cognitive deterioration and will also not hinder social information processing and occupational difficulties. 


\section{Effectiveness of Cognitive Retraining In Chronic Mental Illness}

\section{REFERENCES}

Bell M, Bryson G, \& Greig T (2001) Neurocognitive enhancement therapy with work therapy: effects on neuropsychological test performance. Archives Of General Psychiatry; 58:763768

Bell M, Bryson G, \& Greig T. Neurocognitive enhancement therapy with work therapy: effects on neuropsychological test performance. Archives of General Psychiatry. 2001;58:763768.

Bellack, A., Haas, G., Schooler, N., \& Flory, J.(2000). Effects of behavioural family management on family communication and patient outcomes in schizophrenia. British Journal of Psychiatry, 171, 434-439.

Bora M. (2009), Cognitive impairment in affective psychoses. Schizophrenia Bulletin vol. 36 no. 1 pp. 112-125, 2010.

Conners C., Epstein J., Angold A, \& Klaric J. (2003).Continuous performance test performance in a normative epidemiological sample. Journal of Abnormal Child Psychology ;31:5562.

Corrigan, P., Hirschbeck, J., \& Wolfe, M., (1995). Memory and vigilance training to improve social perception in schizophrenia. Schizophrenia Research 17, 257-265.

Critchley H.D.(2003). Human cingulate cortex and autonomic control. Brain;126, 2139-52.

D’Amato T, Bation R, Cochet A, Jalenques I, Galland F, \& Giraud-Baro E, (2011). A randomized controlled trail of computer-assisted cognitive remediation for schizophrenia. Schizophrenia Research; 125:284-90.

Dickinson D, Tenhula W, Morris S, Brown C, Peer J \& Spencer K, (2010). A randomized controlled trail of computer-assisted cognitive remediation for Schizophrenia. American Journal of Psychiatry; 167: 170-80.

Eack S., Greenwald D., Hogarty S., Cooley S., Di Barry A, \& Montrose D (2009). Cognitive enhancement therapy for early-course schizophrenia: effects of a two-year randomized controlled trail. Psychiatric Services;60:1468-76.

Erickson R, Binder L. (2003) Cognitive deficits among functionally psychotic patients: A rehabilitative perspective. Journal of Clinical and Experimental neuropsychology, 8;257274.

Fan J, Flombaum J, Mc Candliss B., Thomas K., \& Posner M.(2003). Cognitive and brain consequences of conflict. Neuroimage; 18: 42-57.

Fisher M, Holland C, Merzenich M \& Vinogradov S. Using neuroplasticity-based auditory training to improve verbal memory in schizophrenia. American Journal Of Psychiatry. 2009;166:805-811.

Gold, J, Goldberg, R., McNary S.., Dixon, L.S. \& Lehman, A.F., (2002). Cognitive correlates of job tenure among patients with severe mental illness. American Journal Of Psychiatry 159 (8), 1395-1402.

Goldman R, P.S. (1994). Working memory dysfunction in schizophrenia. Special issues: the frontal lobes and neuropsychiatric illness. Journal of Neuropsychiatry Clinical. Neurosci.6, 348-357. 


\section{Effectiveness of Cognitive Retraining In Chronic Mental Illness}

Gururaj, G., Shastry, K. V. R., Chandramouli, A. B., Subbakrishna, D. K., Kraus, J.F.(2005a). Traumatic brain injury. National Institute of Mental Health and Neuro Sciences, Bangalore, Publication No. 61.

Hegde, S., Rao, S. L., \& Raguram, A. (2007). Integrated psychological internvention for schizophrenia. International Journal of Psychosocial Rehabilitation, 11(2), 5-18.

Hurford et al (2011) http://www.psychiatrictimes.com/schizophrenia/cognitive-rehabilitationschizophrenia, accessed on April $24^{\text {th }} 15$ at 11:30 p.m (IST).

Jamuna, N., \& Shibu, P. (2010). Home based cognitive retraining in traumatic brain injury. Indian Journal of Neurotrauma, 93(7), 93-96.

Mc Gurk.(2007), A Meta analysis of cognitive remediation in Schizophrenia. American Journal of Psychiatry, December 164(12): 1791-1802.

Silverstein S.M, Menditto A.A. \& Stuve P.,(2001). Shaping attention span; anoperant conditioning procedure to improve neurocogition and functioning in schizophrenia. Schizophrenia Bulletin;27:247-57.

Srinivasan, L., Thara, R., \& Tirupati, S. N. (2005). Cognitive dysfunction and associated factors in patients with chronic schizophrenia. Indian Journal of Psychiatry, 47(3), 139-143.

Trivedi J.K. (2006). Cognitive deficits in psychiatric disorders: Current status. Indian Journal of Psychiatry Indian J Psychiatry. Jan-Mar; 48(1): 10-20. doi: 10.4103/0019-5545.3161.

Twamley E.W.Jeste D.V. \& Bellack A.S.(2003), A review of cognitive training in schizophrenia. Schizophrenia Bullentin.29:359-82.

Van der Gaag, M., Kern, R.S., Van den Bosch, R.J. \& Liberman, R.P., (2002).A controlled trail of cognitive remediation in schizophrenia. Schizophrenia Bulletin 28 (1), 167-176. 